\title{
Feasibility of Continuous Intraoperative Neural Monitoring During Transoral Endoscopic Thyroidectomy Vestibular Approach in a Porcine Model
}

\section{Abstract}

Background: Experimental study to evaluate feasibility of continuous intraoperative neural monitoring (C-IONM) in transoral endoscopic thyroidectomy vestibular approach (TOETVA).

AU4 Methods: Duroc-Landrace pigs were orally intubated with electromyogram endotracheal tube. Automatic periodic stimulation (APS) electrode was allocated in the operative field through the 5-mm ports. APS was then repose on vagal nerve (VN) with different approaches: (1) median, that is, between sternothyroid and thyroid gland; and (2) lateral, that is, between sternocleidomastoid and sternothyroid. VN was stimulated proximally and distally to the APS location to verify whether the dissection and/or placement determined VN injury. Video presentation is offered.

Results: Assembled APS accessory was feasible in large-brained animals. The two basic options for VN approaches were tested. Baseline obtained had amplitude values $>1000 \mu \mathrm{V}$, bilaterally.

Conclusions: C-IONM was feasible in TOETVA in porcine models, but simplification of electrode design and application is needed.

AU5 Keywords: thyroid surgery, endoscopic thyroidectomy, transoral thyroidectomy, continuous monitoring, recurrent laryngeal nerve, vagal nerve

\section{Introduction}

Ontinuous InTRAOPERATIVE NEURAL MONITORING (CIONM) is an endorsed technology to perceive imminent nerve lesions and to end the associated surgical maneuver and impede permanent recurrent laryngeal nerve (RLN) injury in thyroid surgery. ${ }^{1}$ C-IONM contributes continuous RLN function report, which is useful in complex procedures especially as in endoscopic and robotic thyroidectomy. ${ }^{2} \mathrm{C}$-IONM overcomes the limit of intermittent application (I-IONM), that is, RLN at risk of injury between or proximally to the stimulation sites. ${ }^{1-3}$

With numerous institutions beginning to perform transoral endoscopic thyroidectomy vestibular approach (TOETVA), there is an accretion concern in novel accessories that may early advise for RLN stress. ${ }^{4-7}$

A recent article reports on C-IONM feasibility in transoral endoscopic procedures in humans. ${ }^{8}$
It is identically necessary that the safeness of an original technology and related procedure is verified before it is generally applied on patients.

The purpose of this translational study was to evaluate the feasibility of C-IONM application in TOETVA and describe a step-by-step procedure in a porcine model.

\section{Materials and Methods}

\section{Animal breeds}

Protocol was approved by local Animal Care of Jilin University (China). Two Duroc-Landrace piglets $(25 \mathrm{~kg})(n=4$ RLN, $n=4$ vagal nerves or VNs) underwent general anesthesia via i.v. thiopental $15 \mathrm{mg} / \mathrm{kg}$ administration and oral intubation performed via size number 7ID EMG (electro- 4 AU6 myogram) endotracheal tubes (TriVantage; Medtronic, Jacksonville, FL) to explore the application of C-IONM. Anesthesia

\footnotetext{
AU3 ${ }^{1}$ Department of Thyroid Surgery, China-Japan Union Hospital of Jilin University, Jilin Provincial Key Laboratory of Surgical Translational Medicine, Changchun, China.

${ }^{2}$ Division for Endocrine and Minimally Invasive Surgery, Department of Human Pathology in Adulthood and Childhood "G. Barresi," University Hospital G. Martino, University of Messina, Messina, Italy.

$*$ These authors contributed equally as corresponding authors.
} 
was maintained with sevoflurane $1 \%$ to $2 \%$ and cardiopulmonary monitoring was performed. EMG parameters, including threshold, latency, amplitude, and evoked potentials in swine, are similar to humans. ${ }^{9-14}$

\section{Monitoring equipment and setup}

The monitor (NIM-Response 3.0 System; Medtronic) was set with a response threshold to identify small response at $150 \mu \mathrm{V}$, stimulation rejection artifact at $2.6 \mathrm{~ms}$, and rectangular pulsate-negative stimulus of $100 \mu$ s duration at $4 \mathrm{~Hz}$. Proper EMG tube position was verified by laryngoscope and obtaining first VN V1 stimulation value and $\backslash$ or baseline $>500 \mu \mathrm{V} .^{1,2,11}$ Single-use, incrementing Prass stimulating probe, monopolar, standard flexible tip (product n.8225490; Medtronic), was inserted transcutaneously, midline for complementary intermittent IONM. IONM was offered analogous to standards by the International Neural Monitoring Study Group. ${ }^{11,12}$

\section{TOETVA and C-IONM procedure}

TOETVA procedure has been previously described. ${ }^{5-7}$ $\mathrm{C}$-IONM was delivered by the automatic periodic stimulation (APS; Medtronic) accessory. The APS electrode was wet before to facilitate its sliding into the 5 -mm ports. The outer black clip of the APS electrode was carefully removed. After the creation of the working space, ${ }^{5-7}$ the probe was allocated

F1 in the operative field through the left 5-mm port (Fig. 1). The side of the ports is determined by the dominant side of thyroid disease. The port was then removed by sliding the wire inside until the end and then restored and reinserted. Therefore, the wire of the APS remained between the port and the vestibule. In this way, there was no interference and displacement with the introduction of the endoscopic instruments in the port.

We evaluated two different approaches to the VN, bilaterally and in both pigs.

1. Median, that is, in between the sternothyroid and thyroid gland (Fig. 2a, b).

2. Lateral, that is, between the sternocleidomastoid and sternothyroid (Fig. 3a, b).

The APS was positioned gently on the VN after opening the carotid sheet by a $2-\mathrm{cm}$ pouch. Careful $360^{\circ}$ dissection of the VN with Maryland forceps is required. To prevent VN thermal injuries, energy-based devices were avoided. The APS electrodes were then reposed gently on the VN. During VN dissection and after the C-IONM electrode was placed, the VN was stimulated repeatedly by means of the intermittent stimulating probe, proximally and distally to the location of APS, to verify whether the dissection or electrode placement determined VN injury. After connecting the APS electrode with the monitor system, baselines for the latency and amplitude were graded. Stimulation frequency for C-IONM was set for every second, thus evaluating the RLN and VN constantly. To ensure that the APS probe wire was devoid of 4 AU7 or interfered with the endoscopic view, the APS electrode wires were anchored on the platysma with two stitches from external to internal (Fig. 4). During the experiment, EMG $<$ F4 signals were recorded steadily. An upper limit threshold for the latency $(+10 \%)$ and a lower limit threshold for amplitude $(-50 \%)$ were used as alarm lines. ${ }^{1,2}$ In addition, acoustic and optical signals alerted the surgeon when a preset threshold

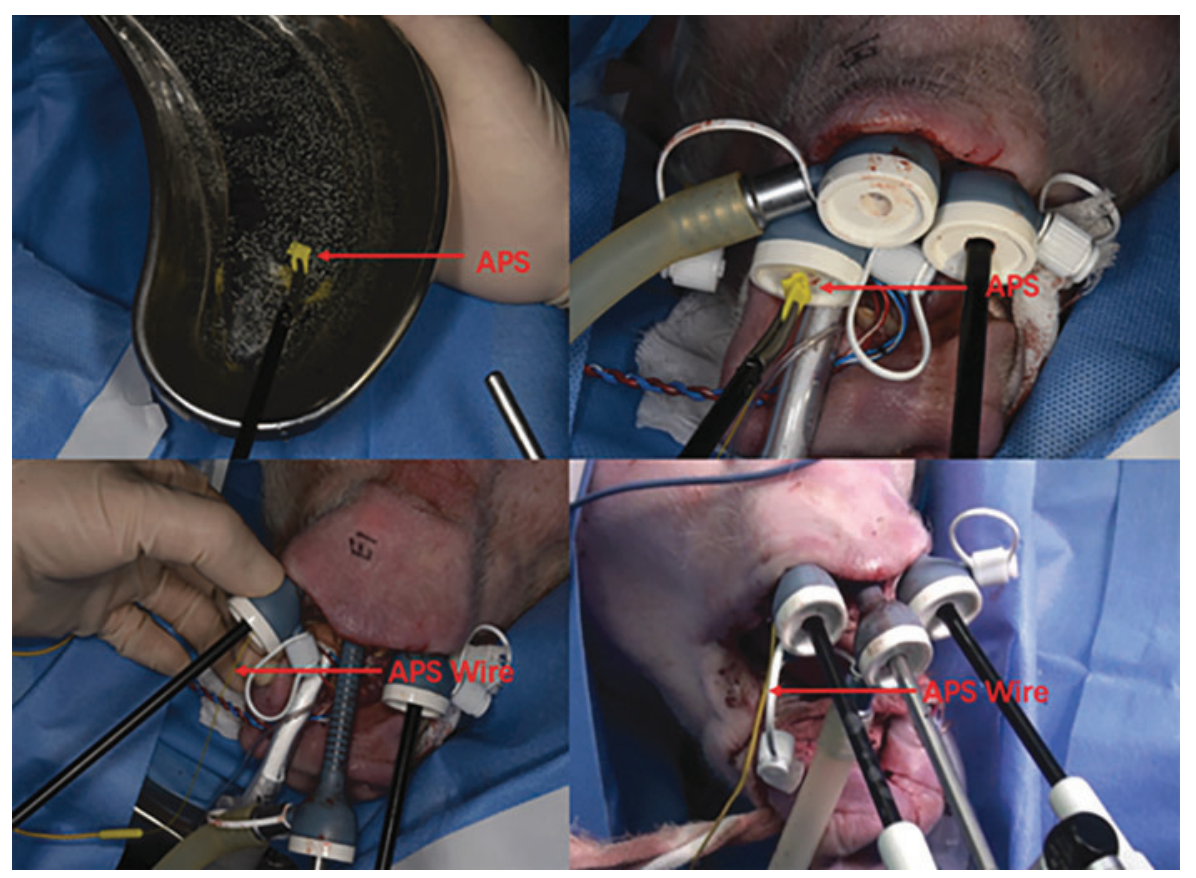

FIG. 1. The APS accessory is wet before to facilitate its sliding into the left 5-mm port. Also, the outer black clip is carefully removed. The APS electrode is placed through the left 5-mm port. The port is then removed by sliding the wire inside until the end and then restored. Therefore, the wire of the APS remains between the port and the vestibule. In this way, there is no interference with the introduction of the endoscopic instruments in the port. The side of the port is determined by the dominant side of thyroid disease. APS, automatic periodic stimulation. 

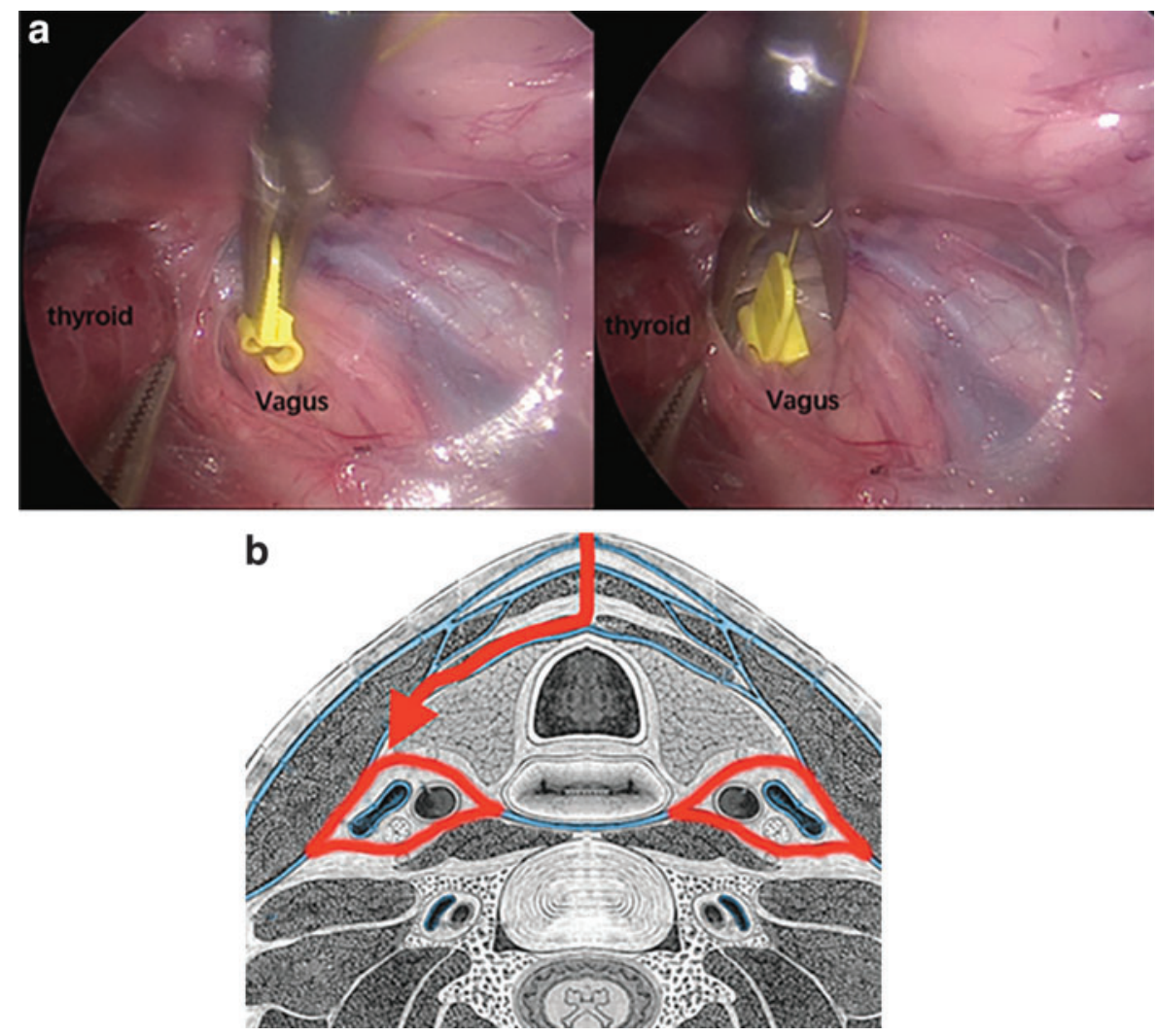

FIG. 2. The anterior median approach (i.e., between sternothyroid and thyroid gland). The APS is positioned gently on the $\mathrm{VN}$ after opening the carotid sheet by a $2-\mathrm{cm}$ pouch. Careful $360^{\circ}$ dissection of the $\mathrm{VN}$ with Maryland forceps is required. To AU12 prevent VN thermal injuries, energy-based devices are avoided. Intraoperative view (a) and scheme (b). VN, vagal nerve.
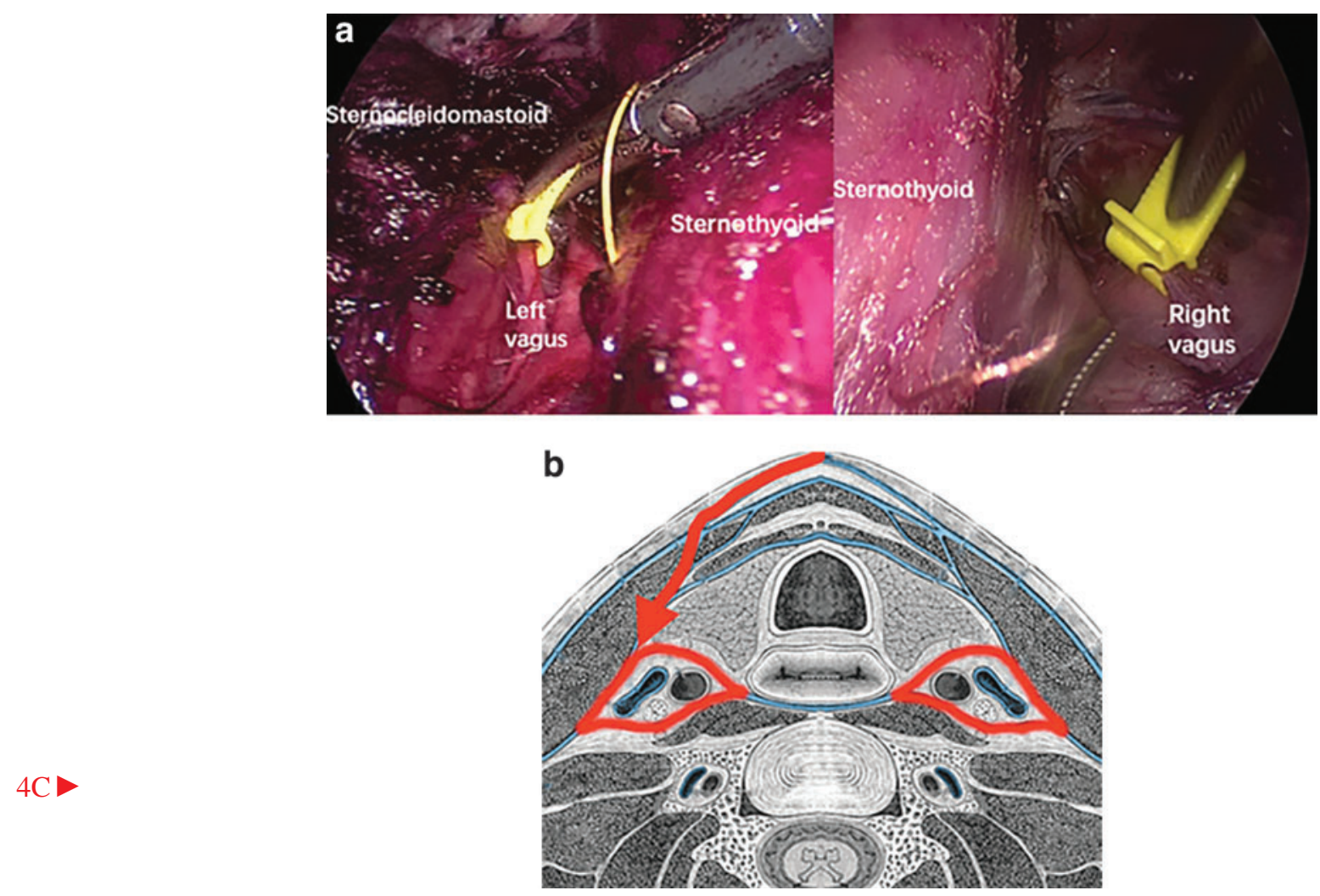

FIG. 3. The modified anterolateral approach to the vagal nerve (i.e., between the sternocleidomastoid and sternothyroid). AU13 Intraoperative view (a) and scheme (b). 


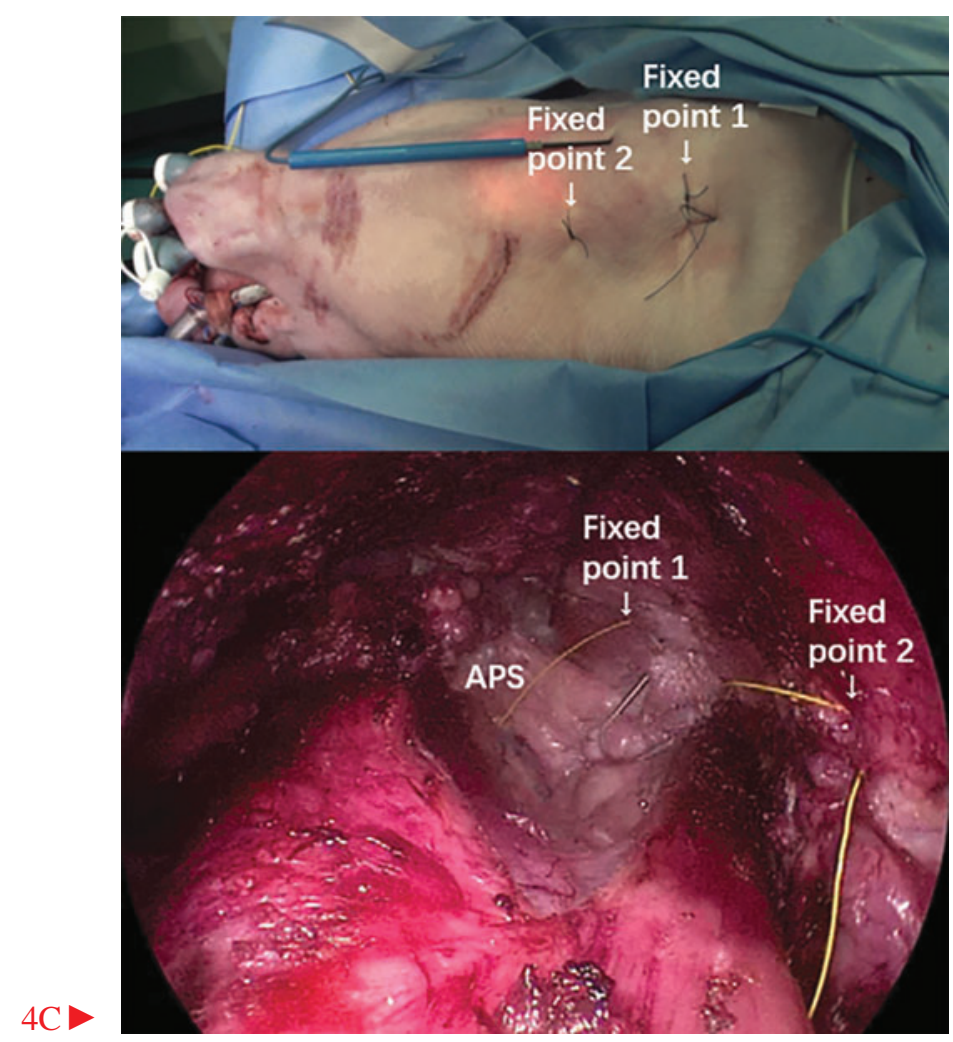

FIG. 4. The APS electrode wires were fixed on the platysma with two external to internal stitches to prevent wire endoscopic view inference during transoral endoscopic thyroidectomy vestibular approach. APS, automatic periodic stimulation. had been crossed or when the electrode had become dislodged. Removal of APS was performed by gently opening and pulling out the pins. Protocol included multiple sequences and test for APS positioning, with different APS sizes $(2$ and $3 \mathrm{~mm}$ ) in distinct VN cervical locations. The TOETVA procedure was done under an operating $30^{\circ}$ endoscope.

\section{Results}

\section{Intermittent monitoring and normative EMG data}

The VNs and the RLNs were identified and stimulated in all procedures bilaterally. We achieved the IONM intermittent standardized technique with V1, R1, R2, V2 determinations: the mean \pm standard deviation (SD) response amplitudes were $1950 \pm 279 \mu \mathrm{V}$ for $V 1$ and $2036 \pm 549 \mu \mathrm{V}$ for $R 1$. Mean response amplitudes of $R 2$ and $V 2$ were $1966 \pm 521 \mu \mathrm{V}$ and $2092 \pm 676 \mu \mathrm{V}$, respectively.

\section{APS implanting}

Supplementary Video S1 (Supplementary Data are avail- 4 SV1 able online at www.liebertpub.com/lap) of the experimental surgical procedure is available (please note that the TOETVA surgery shown in this video is for APS positioning and CIONM demonstration purposes only). Assembled continuous monitoring with APC accessory was feasible in large-brained animals. The APS procedures location ranged between 15-37 4 AU8 minutes long. The two basic options for $\mathrm{VN}$ approaches were successfully tested. The lateral approach to the VN was more demanding, because of the required muscular dissection. The mean \pm SD were $18.5 \pm 8$ minutes for medial approach and $27 \pm 7$ minutes for lateral approach. No major vascular injuries occurred. VN $360^{\circ}$ dissection was achieved without injury confirmed by proximal stimulation (Supplementary

Table 1. Continuous Intraoperative Neural Monitoring Electrodes Available for Thyroidectomy

\begin{tabular}{|c|c|c|c|c|c|c|}
\hline & S Shaped & Anchor & $V 3$ & Delta & Saxophone & $A P S$ \\
\hline Design & Open & Open & Open & Partially closed & Partially closed & Closed \\
\hline VN dissection & Partial & Partial & Partial & $<360^{\circ}$ & $<360^{\circ}$ & $360^{\circ}$ \\
\hline Installation & & & ++ & & + & ++ \\
\hline Size $(\mathrm{mm})$ & $54 \times 8 \times 0.8$ & $25 \times 0.8 \times 18$ & $20.8 \times 4.8$ & $18.05 \times 5 \times 7$ & $17.6 \times$ different & $2-3 \mathrm{~mm}$ \\
\hline Adaptability & + & + & + & ++ & ++ & +++ \\
\hline Versatility & + & + & + & ++ & ++ & +++ \\
\hline Flexibility & +++ & + & + & ++ & ++ & +++ \\
\hline Hindrance & + & + & + & ++ & ++ & +++ \\
\hline Mode of stimulation & Tripolar & Bipolar & Tripolar & Bipolar & Tripolar & Monopolar \\
\hline $\begin{array}{l}\text { Signal stability } \\
\text { Company }\end{array}$ & Langer & Langer & $\begin{array}{l}+ \\
\text { Inomed }\end{array}$ & $\begin{array}{l}+++ \\
\text { Inomed }\end{array}$ & $\begin{array}{l}+++ \\
\text { Langer }\end{array}$ & $\begin{array}{l}+++ \\
\text { Medtronic }\end{array}$ \\
\hline CE market & 2010 & 2009 & 2008 & 2013 & 2013 & 2011 \\
\hline Kind & Reusable & Reusable & - & Disposable & Disposable & Disposable \\
\hline Pulse width & $200 \mathrm{mcs}$ & $200 \mathrm{mcs}$ & $200 \mathrm{mcs}$ & $200 \mathrm{mcs}$ & $200 \mathrm{mcs}$ & $200 \mathrm{mcs}$ \\
\hline Stimulation intensity & $1-2.5$ & $1-2.5$ & $3-5$ & 1 & $1-2.5$ & 1 \\
\hline
\end{tabular}

None of these seems to be easy to apply in TOETVA. Simplification of electrode design, geometry, and application on the VN is advisable in the near future.

AU11 APS, automatic periodic stimulation; CE; TOETVA, transoral endoscopic thyroidectomy vestibular approach; VN, vagal nerve. 
Video S1). APS flexible wire produced no interference with the endoscopic instrumentations and view. There were no broken accessories.

\section{Amplitude baselines}

Baselines obtained had amplitude values $>1000 \mu \mathrm{V}$, bilaterally, in both pigs. The mean \pm SD response amplitudes were $1950 \pm 279 \mu \mathrm{V}$.

\section{Signal stability}

The EMG signals were stable. Nerves showed unchanged EMG signals after complete APS positioning and thyroidectomy. The mean \pm SD response amplitudes were $1920 \pm 279 \mu \mathrm{V}$ for $V 1$ and $2044 \pm 249 \mu \mathrm{V}$ for $R 1$. Mean response amplitudes of $R 2$ and $V 2$ were $2066 \pm 121 \mu \mathrm{V}$ and $1922 \pm 216 \mu \mathrm{V}$, respectively. C-IONM was performed successfully without any adverse combined event of decreased amplitude or increased latency in both the pig models: there was no significant difference in RLN and VN latency (increase) and amplitude (decrease) with procedure. No APS accessory displacement occurred during animal thyroidectomy. C-IONM use was not associated with any cardiovascular sequelae. There were no problems with APS removal from the VN and the surgical field.

\section{Discussion}

Witzel and Benhidjeb ${ }^{15}$ first tested the feasibility of intermittent monitoring for the RLN in a porcine model in TOETVA, in 2009. Authors proved IONM to be a performable procedure in living swine with a long stimulating probe. The RLNs were identified visually and then confirmed with IONM at the beginning (R1) and at the end of the bilateral procedures (R2). ${ }^{15}$

Chen et al. ${ }^{8}$ described foremost the use of C-IONM in 20 TOETVAs (i.e., 28 nerves at risk). C-IONM was achieved using a $\mathrm{C} 2$ monitor and delta stimulating electrode (Inomed, Freiburg, Germany). The flexible stimulating electrode was trans-vestibular inserted, with its cable wire lying outside one trocar. ${ }^{8}$ The VN was anatomized, looped, and then covered by the probe. Alarms were set when the EMG amplitude reduced by $50 \%$ and latency prolonged by $10 \% .^{8}$ The stimulation was set at $0.7 \mathrm{~mA}$ every 1 second. C-IONM procedures were successfully completed. No adverse neural, cardiovascular, or gastrointestinal sequelae happened. The ipsilateral $\mathrm{C}-\mathrm{IONM}$ procedure required a mean of 10.33 minutes. There was one instance of probe displacement in this series. One combined EMG event manifested, which improved after releasing the retractor on the gland. This patient had no RLN paralysis postoperatively. ${ }^{8}$

Here, we described the implantation of APS in a porcine model. Each step of the VN preparation, probe insertion, and monitoring is illustrated so that the end surgeon can replicate the process. The experimental study and video confirmed the technical feasibility of C-IONM on the performance of TOETVA with APS accessory in pig model. Obtained baselines were $>1000 \mu \mathrm{V}$, to test the quality of APS positioning and recording.

Supplementary Video S1 illustrates the implantation procedure and critical steps to ensure quality EMG recordings.
Although technically realizable, we here below introduce some important issues to thoughtfully consider translating the obtained results in humans.

Simplification of C-IONM electrode design and application is advisable in the near future for TOETVA due to the following reasons. (1) Instances of equipment interference with the other endoscopic instruments, in particular with the flexible wire in the surgical field. (2) Nevertheless, it is advisable once inserted, not to pull out of the vestibule the flexible wire, as it is time-consuming to reinsert. (3) C-IONM location requires an additional $360^{\circ}$ dissection of the $\mathrm{VN} .^{16,17}$ All C-IONM technologies available need to dissect the VN by $360^{\circ}$ to accommodate the electrode on the nerve. This procedure can be challenging endoscopically, time-consuming, or even harmful to the nerve and vessels while positioning the accessory and at removal of the electrode.

Furthermore, C-IONM accessory should be versatile because the location of the $\mathrm{VN}$ in relation to the common carotid artery and internal jugular vein in humans is variable..$^{18,19}$ Moreover, carotid arteries kinking is frequent with advancing age. $^{18,19}$

Table 1 summarizes the features of C-IONM electrodes $<\mathrm{T} 1$ available currently for thyroid surgery; none of these seem to be easy to apply in TOETVA. Special care should be taken while handling the APS probe and preparing the VN surface for implantation.

Percutaneous and transcutaneous C-IONM has been described recently and appears to be promising for endoscopic and robotic thyroidectomy. ${ }^{20}$

\section{Acknowledgment}

The present study was financially supported by Jilin provincial special fund for healthcare (Grant Nos. SCZSY201714 and SCZSY201504).

\section{Ethical Approval}

This article does not contain any studies with human participants performed by any of the authors.

\section{Informed Consent}

Informed consent is not applicable to this study.

\section{Authors' Contributions}

Conception and design: H.S. and G.D.; administrative support: G.D.; collection and assembly of data: H.S., G.D., and D.Z.; data analysis and interpretation: H.S., G.D., and D.Z.; article writing: all authors; and final approval of article: all authors.

\section{Disclosure Statement}

D.Z., S.L., G.D., T.W., J.Z., G.X., and H.S. have no conflict of interest to disclose, and no other funding or financial relationship with the surgical industry.

\section{References}

1. Schneider R, Randolph GW, Barczynski M, Dionigi G, Wu CW, Chiang FY, Machens A, Kamani D, Dralle H. Continuous intraoperative neural monitoring of the recurrent 
nerves in thyroid surgery: A quantum leap in technology. Gland Surg 2016;5:607-616.

2. Schneider R, Sekulla C, Machens A, Lorenz K, Nguyen Thanh P, Dralle H. Postoperative vocal fold palsy in patients undergoing thyroid surgery with continuous or intermittent nerve monitoring. Br J Surg 2015;102:1380-1387.

3. Dionigi G, Van Slycke S, Boni L, Rausei S, Mangano A. Limits of neuromonitoring in thyroid surgery. Ann Surg 2013;258:e1-e2.

4. Kim HY, Chai YJ, Dionigi G, Anuwong A, Richmon JD. Transoral robotic thyroidectomy: Lessons learned from an initial consecutive series of 24 patients. Surg Endosc 2018; 32:688-694.

5. Anuwong A, Sasanakietkul T, Jitpratoom P, Ketwong K, Kim HY, Dionigi G, Richmon JD. Transoral endoscopic thyroidectomy vestibular approach (TOETVA): Indications, techniques and results. Surg Endosc 2018:32:456-465.

6. Russell JO, Clark J, Noureldine SI, Anuwong A, Al Khadem MG, Yub Kim H, Dhillon VK, Dionigi G, Tufano RP, Richmon JD. Transoral thyroidectomy and parathyroidectomy-A North American series of robotic and endoscopic transoral approaches to the central neck. Oral Oncol 2017;71:75-80.

7. Dionigi G, Bacuzzi A, Lavazza M, Inversini D, Boni L, Rausei S, Kim HY, Anuwong A. Transoral endoscopic thyroidectomy: Preliminary experience in Italy. Updates Surg 2017;69:225-234.

8. Chen HK, Chen CL, Wen KS, Lin YF, Lin KY, Uen YH. Application of transoral continuous intraoperative neuromonitoring in natural orifice transluminal endoscopic surgery for thyroid disease: A preliminary study. Surg Endosc 2018;32:517-525.

9. Randolph GW. Surgical anatomy of the recurrent laryngeal nerve. In: Randolph GW (ed). Surgery of the Thyroid and Parathyroid Glands. Philadelphia, PA: Saunders, 2003, pp. 300-342.

10. Wu CW, Lu IC, Randolph GW, et al. Investigation of optimal intensity and safety of electrical nerve stimulation during intraoperative neuromonitoring of the recurrent laryngeal nerve: A prospective porcine model. Head Neck 2010;32:1295-1301.

11. Randolph GW, Dralle $\mathrm{H}$; International Intraoperative Monitoring Study Group, Abdullah H, Barczynski M, Bellantone R, Brauckhoff M, Carnaille B, Cherenko S, Chiang FY, Dionigi G, Finck C, Hartl D, Kamani D, Lorenz K, Miccolli P, Mihai R, Miyauchi A, Orloff L, Perrier N, Poveda MD, Romanchishen A, Serpell J, Sitges-Serra A, Sloan T, Van Slycke S, Snyder S, Takami H, Volpi E, Woodson G. Electrophysiologic recurrent laryngeal nerve monitoring during thyroid and parathyroid surgery: International standards guideline statement. Laryngoscope 2011;121:S1-S16.

12. Dionigi G, Boni L, Rovera F, Bacuzzi A, Dionigi R. Neuromonitoring and video-assisted thyroidectomy: A prospective, randomized case-control evaluation. Surg Endosc 2009;23:996-1003.

13. Lee HY, You JY, Woo SU, Son GS, Lee JB, Bae JW, Kim HY. Transoral periosteal thyroidectomy: Cadaver to human. Surg Endosc 2015;29:898-904.
14. Lee HY, Hwang SB, Ahn KM, Lee JB, Bae JW, Kim HY. The safety of transoral periosteal thyroidectomy: Results of Swine models. J Laparoendosc Adv Surg Tech A 2014;24: 312-317.

15. Witzel K, Benhidjeb T. Monitoring of the recurrent laryngeal nerve in totally endoscopic thyroid surgery. Eur Surg Res 2009;43:72-76.

16. Dionigi G, Kim HY, Wu CW, Lavazza M, Materazzi G, Lombardi CP, Anuwong A, Tufano RP. Neuromonitoring in endoscopic and robotic thyroidectomy. Updates Surg 2017; 69:171-179.

17. Dionigi G, Donatini G, Boni L, Rausei S, Rovera F, Tanda ML, Kim HY, Chiang FY, Wu CW, Mangano A, Rulli F, Alesina PF, Dionigi R. Continuous monitoring of the recurrent laryngeal nerve in thyroid surgery: A critical appraisal. Int J Surg 2013;11(Suppl 1):S44-S46.

18. Dionigi G, Chiang FY, Rausei S, Wu CW, Boni L, Lee KW, Rovera F, Cantone G, Bacuzzi A. Surgical anatomy and neurophysiology of the vagus nerve (VN) for standardised intraoperative neuromonitoring (IONM) of the inferior laryngeal nerve (ILN) during thyroidectomy. Langenbecks Arch Surg 2010;395:893-899.

19. Shoja MM, Ardalan MR, Tubbs RS, Loukas M, Vahedinia S, Jabbary R, Jalilvand M, Shakeri A. The relationship between the internal jugular vein and common carotid artery in the carotid sheath: The effects of age, gender and side. Ann Anat 2008;190:339-343.

20. Suh I, Yingling C, Randolph GW, Duh QY. A novel method of neuromonitoring in thyroidectomy and parathyroidectomy using transcutaneous intraoperative vagal stimulation. JAMA Surg 2016;151:290-292.

Address correspondence to: Hui Sun, MD, PhD

Department of Thyroid Surgery

China-Japan Union Hospital of Jilin University Jilin Provincial Key Laboratory of Surgical Translational Medicine 126 Xiantai Blvd. Changchun, Jilin $\varangle$ AU10 China

E-mail: thyroidj1@163.com

Gianlorenzo Dionigi, MD, FACS

Division for Endocrine and Minimally Invasive Surgery Department of Human Pathology in Adulthood and Childhood "G. Barresi" University Hospital G. Martino University of Messina Via C. Valeria 1 Messina, Sicily 98125 Italy

E-mail: gdionigi@unime.it 


\section{AUTHOR QUERY FOR LAP-2018-0054-VER9-ZHANG_1P}

AU1: Please review all authors' surnames for accurate indexing citations.

AU2: Please provide degrees of the authors, as in $\mathrm{MD}, \mathrm{PhD}$, etc.

AU3: Please check the correctness of authors' affiliations.

AU4: "EMG" has been expanded as "electromyogram." Please confirm.

AU5: Please note that as per Journal style maximum of 6 keywords only allowed. Hence, we have deleted 1 keyword in the article. Please check.

AU6: "EMG" has been defined as "electromyogram." Please confirm.

AU7: Please check the edits made to the sentence "To ensure that the APS probe wire...."

AU8: Please rewrite the sentence "The APS procedure location...." for clarity.

AU9: Refs. "16-20" have been renumbered to maintain sequential order of citations in the text. Please check.

AU10: Please provide the zip code in corresponding author address.

AU11: Please define "CE.'

AU12: Please mention what the red arrow indicates in Figure "2b."

AU13: Please mention what the red arrow indicates in Figure "3b."

\section{EDITOR QUERY FOR LAP-2018-0054-VER9-ZHANG_1P}

EQ1: We have retained "Ethical Approval," “Informed Consent,” and “Authors' Contributions” sections as it is. Please confirm and check the placement. 